\title{
基于 MODBUS 实现 HART 仪表与西门子 PLC 之间的通信
}

\section{Communication Between HART Instrument and Siemens PLC Based on MODBUS}

\author{
刘三廷 胡文文 \\ Santing Liu Wenwen $\mathrm{Hu}$ \\ 兰州石化电仪事业部 中国・甘肃 兰州 730060 \\ Lanzhou Petrochemical Electrical Equipment Division, Lanzhou, Gansu, 730060, China
}

摘 要: 结合实际案例,阐述了现场 HART 协议仪表与西门子 PLC之间的通信, 介绍了 MODBUS 协议及其数据传输过程。 实践证明,该方式实现现场 HART 仪表与西门子 PLC之间数据的快速发送和接收,数据显示稳定、准确,符合工艺操作要求。

\begin{abstract}
Combined with the actual case, the communication between HART protocol instrument and Siemens PLC is described, and MODBUS protocol and its data transmission process are introduced. Practice has proved that this method can realize the data fast sending and receiving between HART instrument and Siemens PLC, and the data display is stable and accurate, which meets the requirements of process operation.
\end{abstract}

关键词:西门子 PLC;MODBUS 协议;HART 协议仪表

Keywords : Siemens PLC; MODBUS protocol; HART protocol instrument

DOI : $10.36012 /$ peti.v2i3.2063

\section{1 引言}

在当代社会的生产企业中, DCS、PLC、ESD、SIS、ITCC、 GDS 系统及智能化仪表已广泛应用到生产装置现场, 特别是 带有通信功能的智能仪表已成为世界各国研究的重点。本文 介绍了西门子 PLC 与现场 HART 仪表之间的通信步骤, 结 合嘉兴市松茂电子有限公司的 HART 智能转换器 SM100-W 将 HART 信号转换成 MODBUS 通信协议的应用方法, 为该 项技术的推广应用提供了参考依据。

\section{2 西门子 PLC 系统数据采集方法}

西门子 PLC 模拟量数据表示方法为现场变送器输出标准 的 4 20mA 电流信号送至模拟量输入模块, 在模拟量输入模 块的每一通道都有一个 $\mathrm{A} / \mathrm{D}$ (模拟量转为数字量)转换器将现 场电信号转换为 PLC 处理器 (CPU) 能够识别的数字量, 模拟 量 4 20mA 经 A/D 线性转换后的量程为 6400 32 000, 显示值 可以通过如下公式显示到操作站：显示值 $=(A / D$ 转换值 $6400) /(25600 \times$ 仪表量程)。累积值通过瞬时值除以 36000 , 再 $100 \mathrm{~ms}$ 进行一次累积,这种计算方式随着时间的推移偏差 将越来越大。据统计, 经过 3 个月的累积, 操作站显示累积量
偏差值将达到 5\% 10\%，基于 MODBUS 实现 HART 仪表与 西门子 PLC 之间的数据通信可以解决这一偏差 ${ }^{[1]}$ 。

\section{HART 仪表与西门子 PLC 通信基于MOD- BUS 实现方法}

\section{1 通信过程}

MODBUS 协议是通信双方都要遵守的规则, 是网络内通 信的语言, 协调网络内通信的正常运行, 以到达互相认识的目 的; 通信过程的实质就是数据在各个层次的传输过程, 数据传 输, 实际的物理通信过程是经过上位机的各个层次从上到下 传递到物理通道, 然后再传递到接收端的最底层, 经过从下到 上各层传递, 最后到下位机的应用进程, 最后实现数据通信。

\section{2 实现方法总体设计思路}

\subsection{1 质量流量计变送器实现思路}

将各台质量流量计变送器输出 4 20mA 信号线接入到 8 通道 HART 智能转换器相应的 LOOP 回路中并设置变送器 的轮询地址为 1 8,1 8 地址分别对应的 FT-101 FT-108 的 轮询地址。

(下转第 22 页) 
购人中应格外重视进项税额; 在向相应科目计入原材料时, 应以不含税金额的方式, 才能结转至工程施工科目。

在营改增背景下的会计核算工作, 相较于营业税制下的 复杂性更强, 需要从业人员掌握更多的理论知识和专业技 能。例如, 营改增后原材料的人账成本, 是需要将增值税和进 项税额剔除之后的, 不含税数的版本, 入账成本也远低于营 业税核算时, 从而为电力施工企业创造更多的利润。另外, 企 业还需注重增值税销项税额不能纳入收入中, 主营业务收入 计算需以不含税数据为参考, 经实践证明, 这样会降低当期 计人损益的营业利润,进而造成企业利润下降的后果。

以一般纳税人的电力施工企业为例, 在营增改后与营业 税制的差异, 就在于其收入需将 $11 \%$ 的税率作为根据, 来将 销项税额剔除, 这就会使企业利润下降; 总成本中的原材料, 需以 $17 \%$ 的税率进行进项税额剔除, 企业利润则会增加。若 原材料所占的比重较大, 人账成本缩减程度一般会高于入账 收入的缩减程度, 进而使利润上升; 若工程中原材料的占比 比较小, 以“甲供材” 的电力工程施工形式为例, 则对于电力 施工企业来讲, 税负会增加、利润会减少。因此,企业应尽可
能地争取原材料自购, 从而提高自身在工程建设中的收益 ${ }^{[3]}$ 。

\section{4 结语}

综上所述, 通过对营改增背景下企业税负与会计核算所 受影响的分析, 能帮助电力施工企业更快融入新的运营环 境, 在提高税收、会计核算等各项工作效率和质量的基础上, 促进企业内部管理水平的整体提升。尤其是现如今电力施工 市场的竞争越来越激烈, 电力施工企业若想缓解自身承受的 市场压力, 就必须明确营改增对税负和会计核算的影响, 并 以此为基础实现对其转变方向的掌握, 如此才能在充分发挥 二者重要作用的同时, 为企业创造更广阔的发展空间。

\section{参考文献}

[1] 张国明. 营改增对电力施工企业税负及会计核算影响的研究 [D].济南:山东财经大学, 2017 .

[2] 邓伟妍. “营改增”对电力施工企业的纳税影响及应对策略[J]. 财 会学习,2016(6):173-174.

[3] 梁依岗.刍议 “营改增”对建安类电力企业的影响及税收筹划[J]. 财政监督,2012(29):64-65.

\section{(上接第 15 页)}

\subsubsection{HART 智能转换器实现思路}

将 8 通道 HART 智能转换器 RS485 通信输出端子链接 至PLC CP341 MODBUS 通信卡的通信端子上, 设置 SM100-W 智能转换器串行口参数、修改 RS485 通信数据的波特率及校 验位、修改 MODBUS 从机地址及 HART 指令通信时间, 选择 不同接入通道仪表进行参数配置。

\subsection{3 西门子 PLC 实现思路}

在西门子 S7-300/400 PLC STEP7 下位组态软件的 HARDWARE 硬件组态中安装 CP341 的 device 并完成主从 站设置, 下载配置, 控制器重启后完成硬件组态; 在软件功能 块组态 OB1 中添加通信功能块, 完成相应的软件组态, 完成 通信配置。

\section{3 通信过程的具体实现方法}

\subsection{1 质量流量计变送器参数具体设置方法}

HART(Highway Addressable Remote Transducer), 可寻址 远程传感器高速通道的开发通信协议。通过它可以对智能仪 表进行配置和组态, 在回路中的任何地方能不分极性地并联 通信。为使 HART 手操器能正常工作, HART 回路中至少有 $250 \Omega$ 的电阻。 $\mathrm{E}+\mathrm{H}$ 及罗斯蒙特质量流量计, 用 HART475 通
信可以读取流量计内部的 PV (当前流量测量值)、累积流量 值、温度测量值及压力测量值等许多参数。

\subsubsection{HART 智能转换器参数具体设置方法}

SM100-W 系列 HART 智能转换器是采用 ARM 微处理 器, 具有很高的可靠性及稳定性。智能转换器配有标准的 RS485 接口及网关, 能与有 HART 协议的智能仪表进行数据 透明传输或者使用 MODBUS_RTU 协议读取数据, 保证数据 进行实时传输。多台 HART 协议智能仪表被 DCS 系统或者 PLC 采集后, 在不影响原来使用的情况下, 采用 SM100-W 智 能转换器直接取出 HART 协议数字信号, 转换成 RS485 接 口,MODBUS RTU 协议送至 PLC 系统。

\section{4 结语}

笔者通过总结 PLC 系统及现场智能仪表维护经验, 结合 日常工作中遇到的难题, 提出攻关方案及解决方法, 成功地 解决计量仪表实际累积值与 PLC 累积值不一致的问题, 为正 在使用西门子 S7-400 PLC 的同行提供了很多宝贵经验。

\section{参考文献}

[1] 李如甲, 程武山, 董林.PLC 与智能仪表的通讯设计与实现[J].上 海工程技术大学学报,2010,24(4):346-350. 